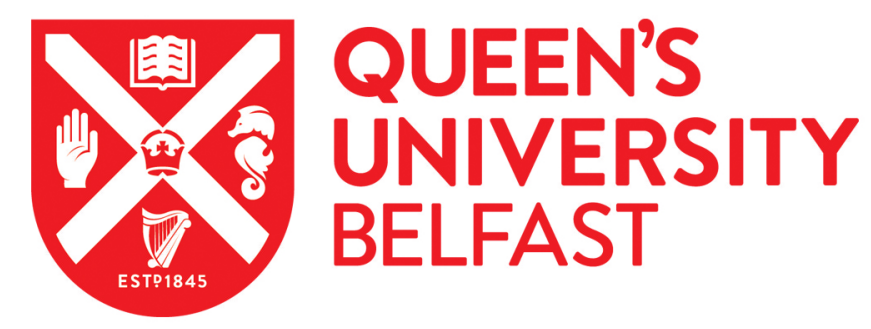

\title{
A finite fracture mechanics model for the prediction of the open-hole strength of composite laminates
}

Camanho, P. P., Erçin, G. H., Catalanotti, G., Mahdi, S., \& Linde, P. (2012). A finite fracture mechanics model for the prediction of the open-hole strength of composite laminates. Composites Part A: Applied Science and Manufacturing, 43(8), 1219-1225. https://doi.org/10.1016/j.compositesa.2012.03.004

Published in:

Composites Part A: Applied Science and Manufacturing

Document Version:

Peer reviewed version

Queen's University Belfast - Research Portal:

Link to publication record in Queen's University Belfast Research Portal

Publisher rights

Copyright 2012 Elsevier

This manuscript version is made available under the CC-BY-NC-ND 4.0 license (http://creativecommons.org/licenses/by-nc-nd/4.0/), which permits distribution and reproduction for non-commercial purposes, provided the author and source are cited.

\section{General rights}

Copyright for the publications made accessible via the Queen's University Belfast Research Portal is retained by the author(s) and / or other copyright owners and it is a condition of accessing these publications that users recognise and abide by the legal requirements associated with these rights.

Take down policy

The Research Portal is Queen's institutional repository that provides access to Queen's research output. Every effort has been made to ensure that content in the Research Portal does not infringe any person's rights, or applicable UK laws. If you discover content in the Research Portal that you believe breaches copyright or violates any law, please contact openaccess@qub.ac.uk. 


\title{
A finite fracture mechanics model for the prediction of the notched strength of composite laminates
}

\author{
P.P. Camanho ${ }^{\text {a,* }}$, G.H. Erçin ${ }^{\text {b }}$, G. Catalanotti ${ }^{\text {a }}$, S. Mahdi ${ }^{\text {, }}$, \\ P. Linde ${ }^{\mathrm{d}}$ \\ ${ }^{a}$ DEMec, Faculdade de Engenharia, Universidade do Porto, Rua Dr. Roberto \\ Frias, 4200-465, Porto, Portugal \\ ${ }^{\mathrm{b}}$ INEGI, Instituto de Engenharia Mecânica e Gestão Industrial, Rua Dr. Roberto \\ Frias 400, 4200-465, Porto, Portugal \\ ' AIRBUS Operations SAS, 316, Route de Bayonne, 31060 Toulouse Cedex 03, \\ France \\ d AIRBUS Operations GmbH, Kreetslag 10, 21129 Hamburg, Germany
}

\begin{abstract}
A new model based on finite fracture mechanics is proposed to predict the openhole tensile strength of composite laminates. Failure is predicted when both stressbased and energy-based criteria are satisfied. The material properties required by the model are the laminate unnotched strength and fracture toughness. No empirical adjusting parameters are required. Using experimental data obtained in quasiisotropic carbon-epoxy laminates it is concluded that the model predictions are very accurate, resulting in improvements over the traditional strength prediction methods. It also is shown that the proposed finite fracture mechanics model can be used
\end{abstract}


to predict the brittleness of different combinations of materials and geometries.

Key words: A. Polymer-matrix composites (PMCs), B. Fracture, C. Analytical modelling.

\section{$1 \quad 1 \quad$ Introduction}

2 The aerospace industry strives for accurate, physically-based and fast strength

3 prediction methods for composite laminates with stress concentrations. While

4 the two first conditions can be satisfied using appropriate non-linear finite ele-

5 ment (FE) models [1]-[5], the third one cannot. Implicit non-linear FE models

6 that include material instabilities result in severe convergence difficulties and

7 require very fine meshes with element sizes typically smaller than $1 \mathrm{~mm}$. The

8 computing time of explicit non-linear FE models is partially defined by the

9 stable time increment that decreases with the element size. Both approaches

10 normally result in long computing times that are not acceptable for prelimi-

11 nary sizing and for the optimization of aircraft structural details.

12 The most widely used design method for composite laminates with stress

13 concentrations that is suitable for preliminary sizing and optimization is the

14 point stress or the average stress models proposed by Whitney and Nuismer

15 [6], or variations of thereof [7]. The point stress model assumes that failure

16 takes place when the stress at a given distance from the notch boundary

17 (the 'characteristic distance') reaches the unnotched strength of the laminate,

18 whereas the average stress model predicts failure when the average stress over a

\footnotetext{
* Corresponding author

Email address: pcamanho@fe.up.pt (P.P. Camanho).
} 
19

25 26

27 An alternative method for the strength prediction of composite laminates 28 loaded in tension containing notches or cracks based on the numerical imple29 mentation of cohesive formulations were developed Bäcklund et al. [9]-[12]. so The damage mechanisms that occur at the vicinity of a crack or hole are 31 lumped into a damage zone, where a linear relation between the cohesive trac32 tion and the crack opening is assumed. A traction-free crack develops when 33 the dissipated energy equals the fracture toughness of the laminate. While 34 this method is based on sound mechanical models, the need for a numerical 35 implementation renders it unsuitable for fast predictions.

36 Based on the previous observations, the objective of this paper is to develop 37 a fast strength prediction method for composite laminates with circular holes 38 loaded in tension. The strength prediction method should be based on inde39 pendently measured material properties, and it must not require any type of 40 calibration for different hole sizes or specimen widths.

${ }_{41}$ The model developed is based on the concept of finite fracture mechanics 42 that was originally introduced by Leguillon [13]. Finite fracture mechanics 43 models assume that crack propagation results from the simultaneous fulfilment 
44 of a stress-based criterion and an energy-based criterion. In addition, it is 45 considered that failure occurs by the propagation of kinematically admissible 46 cracks with finite sizes.

${ }_{47}$ The finite fracture mechanics criteria predict failure based on two conditions 48 [14]: the stress ahead of a crack tip averaged over a distance $l$ reaches the ma49 terial strength $X_{T}^{L}$, i.e. $\int_{a}^{a+l} \sigma(x) d x=X_{T}^{L} l$. In addition, the energy available 50 to propagate the crack a finite distance $l$ must be equal to a critical value 51 that is defined by the fracture toughness of the material. This condition, es${ }_{52}$ tablished using the stress intensity factor $\mathcal{K}$ and its critical value $\mathcal{K}_{I c}$, reads ${ }_{53}[14]: \int_{a}^{a+l} \mathcal{K}_{I}^{2}(a) d a=\mathcal{K}_{I c}^{2} l$.

${ }_{54}$ Finite fracture mechanics models have been applied to the prediction of frac55 ture of unidirectional composites under off-axis tension [15], sharp V-notches 56 in isotropic materials [16]-[17], three-point bending tests in notched and un57 notched specimens [14], [18], bi-material joints [19], and free-edge delamination $58 \quad[20]$.

\section{${ }_{59} 2$ Finite fracture mechanics model for notched composites}

60 Consider a composite laminate with a central circular hole with a diameter $d$, ${ }_{61}$ radius $R$ and width $W$ loaded in tension (Figure 1 ).

62 [Fig. 1 about here.]

63 For the loading conditions shown in Figure 1, and assuming that the lay-up 64 of the laminate leads to either the brittle or pull-out failure modes defined ${ }_{65}$ by Green et al. [21], the propagation of the macro-crack that leads to final 
69 when the following system of equations is satisfied:

$$
\left\{\begin{array}{c}
\frac{1}{l} \int_{R}^{R+l} \sigma_{y y}(x, 0) d x=X_{T}^{L} \\
\frac{1}{l} \int_{R}^{R+l} \mathcal{K}_{I}^{2}(a) d a=\mathcal{K}_{I c}^{2}
\end{array}\right.
$$

70 where $X_{T}^{L}$ is the unnotched strength of the laminate, $\mathcal{K}_{I c}$ is the mode I fracture 71 toughness of the laminate, and $l$ is the crack extension at failure. The first 72 equation in (1) corresponds to the average-stress model [6]; therefore, the 73 proposed finite fracture model enriches the average-stress model using a second 74 equation that represents an energy balance that must be satisfied during crack 75 propagation. Taking into account that the system of equations (1) yields the 76 remote notched strength and the crack extension at failure, there is no need 77 to use an empirical 'characteristic distance' identified from one notched test 78 specimen [6].

79 The stress distribution along the x-axis, $\sigma_{y y}(x, 0)$, is obtained as [22]:

$$
\sigma_{y y}(x, 0)=R_{K} \frac{\sigma^{\infty}}{2}\left[2+\xi^{2}+3 \xi^{4}-\left(K_{T}^{\infty}-3\right)\left(5 \xi^{6}-7 \xi^{8}\right)\right], \xi=\frac{R}{x}
$$

80 where $\sigma^{\infty}$ is the remote stress, $K_{T}^{\infty}$ is the stress concentration factor of an 81 infinite plate containing a circular hole, and $R_{K}$ is the finite width correction 
82 factor. These parameters are defined as [22]:

$$
\begin{aligned}
K_{T}^{\infty} & =1+\sqrt{\frac{2}{A_{22}}\left(\sqrt{A_{11} A_{22}}-A_{12}+\frac{A_{11} A_{22}-A_{12}^{2}}{2 A_{66}}\right)} \\
R_{K} & =\frac{K_{T}}{K_{T}^{\infty}}= \\
& =\left\{\frac{3(1-2 R / W)}{2+(1-2 R / W)^{3}}+\frac{1}{2}\left(\frac{2 R}{W} M\right)^{6}\left(K_{T}^{\infty}-3\right)\left[1-\left(\frac{2 R}{W} M\right)^{2}\right]\right\}^{-1}
\end{aligned}
$$

83 where $A_{i j}$ are the components of the laminate in-plane stiffness matrix [24], 84 and $M$ is calculated as:

$$
M^{2}=\frac{\sqrt{1-8\left[\frac{3(1-2 R / W)}{2+(1-2 R / W)^{3}}-1\right]}-1}{2(2 R / W)^{2}}
$$

${ }_{85}$ The stress intensity factor $\mathcal{K}_{I}$ corresponding to two symmetric cracks emanat86 ing from a plate with a central circular hole is given for an isotropic plate as $87 \quad[23]$ :

$$
\mathcal{K}_{I}=\sigma^{\infty} F_{h} F_{w} \sqrt{\pi a}
$$

88 with:

$$
\begin{gathered}
F_{h}=\sqrt{1-\frac{R}{a}} f_{n} \\
f_{n}=1+0.358 \lambda+1.425 \lambda^{2}-1.578 \lambda^{3}+2.156 \lambda^{4}, \lambda=R / a
\end{gathered}
$$

89 and: 


$$
F_{w}=\sqrt{\sec \left(\frac{\pi R}{W}\right) \sec \left(\frac{\pi a}{W}\right)}
$$

90 Observing equations (1), (2) and (6) it becomes clear why the 'characteristic ${ }_{91}$ distance' $l$ used in the average-stress model [6], which corresponds to the first 92 equation in (1), cannot be a material property: the geometric terms included in 93 the solution for the stress distribution, equation(2), and in the solution for the 94 stress intensity factor, equation (6), imply that the solutions of the system of 95 equations (1) are functions of both the geometry and the material properties. 96 The fact that the 'characteristic distance' is a function of the geometry of 97 the specimen has been demonstrated by several experimental results, see for 98 example [8].

99 Using (2) and (6) in (1), and dividing the second equation (1) by the square 100 of the first one yields:

$$
\frac{4 l \pi \int_{R}^{R+l}\left(F_{h} F_{w}\right)^{2} a d a}{R_{K}^{2}\left\{\int_{R}^{R+l}\left[2+\xi^{2}+3 \xi^{4}-\left(K_{T}^{\infty}-3\right)\left(5 \xi^{6}-7 \xi^{8}\right)\right] d x\right\}^{2}}=\left(\frac{\mathcal{K}_{I c}}{X_{T}^{L}}\right)^{2}
$$

101 The integral in the denominator of equation (10) can be solved analytically, 102 whereas the integral in the numerator cannot. Using Simpson's rule [25] to 103 numerically integrate the numerator of (10) the resulting non-linear equation 104 can be solved for $l$. Once $l$ is known, it is possible to calculate the remote 105 stress at failure, $\bar{\sigma}^{\infty}$, using one of the equations (1).

106 It should be noted that the correction factors applied to the stress intensity 107 factor should account for the orthotropy of the composite material [26]. How108 ever, for quasi-isotropic laminates the stress intensity factor calculated using 109 (6) is accurate and no additional correction factors are required. 


\section{Material selection and characterization}

111 The material selected for this work is the Hexcel IM7-8552 carbon epoxy uni112 directional laminate. After laying-up, the material was cured according to the 113 manufacturer's specifications, with temperature stages of $110^{\circ} \mathrm{C}$ during 1 hour, 114 followed by $180^{\circ} \mathrm{C}$ for 2 hours using heating and cooling rates of $3^{\circ} \mathrm{C} / \mathrm{min}$. 115 The pressure of 7 bar was applied during the duration of the curing cycle. To 116 validate the finite fracture mechanics model using previously obtained experi117 mental data $[5]$ the $[90 / 0 / \pm 45]_{3 s}$ lay-up is selected, corresponding to laminates 118 with a nominal thickness of $3 \mathrm{~mm}$. ${ }_{127}(\mathrm{STDV})$.

128

129 The unnotched tensile strength of the laminate, $X_{T}^{L}$, was measured using five 130 test specimens. The tests were performed following the ASTM standard D1313039 [27], and the average value obtained was $X_{T}^{L}=845.1 \mathrm{MPa}$ (standard 132 deviation of $47 \mathrm{MPa}$ ).

[Table 1 about here.] 
133 There are no standard test methods to measure the fracture toughness of the 134 laminate. Taking into account the simplicity of the geometry and of the data 135 reduction method, specimens with a central crack are selected to measure this 136 property.

137 Four specimens with central cracks with a length $2 a=15 \mathrm{~mm}$ were tested. 138 Two of the test specimens are $45 \mathrm{~mm}$ wide and the other two are $48 \mathrm{~mm}$ wide. 139 The specimens were loaded in tension at a rate of $2 \mathrm{~mm} / \mathrm{min}$ until final failure. 140 All the specimens tested failed by net-tension, with crack propagation from ${ }_{141}$ the original central crack towards the edges of the specimen.

142 The calculation of the fracture toughness is based on the finite fracture me143 chanics analysis of the specimen with a central crack. Failure occurs when the 144 following system of equations is satisfied:

$$
\left\{\begin{array}{c}
\frac{1}{l} \int_{a}^{a+l} \sigma_{y y}(x, 0) d x=X_{T}^{L} \\
\frac{1}{l} \int_{a}^{a+l} \mathcal{K}_{I}^{2}(a) d a=\mathcal{K}_{I c}^{2}
\end{array}\right.
$$

145 For sufficiently large $W / a$ ratios, the stress distribution used in equation (11) 146 reads:

$$
\sigma_{y y}(x, 0)=\frac{\sigma^{\infty} x}{\sqrt{x^{2}-a^{2}}}
$$

147 and the stress intensity factor is given by: 


$$
\mathcal{K}_{I}=\sigma^{\infty} \sqrt{\pi a}
$$

148

149

150

151

152 deviation of $1.6 \mathrm{MPa} \sqrt{\mathrm{m}})$.

${ }_{153}$ It is interesting to note that this value is quite close to that obtained from the 154 direct application of Linear-Elastic Fracture Mechanics $(45.1 \mathrm{MPa} \sqrt{\mathrm{m}})$. This 155 means that it is possible to use models that relate the fracture toughness of 156 the $0^{\circ}$ ply to the fracture toughness of a multidirectional laminate [29] in the 157 finite fracture mechanics model without incurring in significant errors.

\section{$158 \quad 4$ Model validation}

159 The model proposed in this paper is validated by comparing its predictions 160 with experimental data obtained in IM7-8552 CFRP open-hole tensile tests $161[5],[21]$.

162 Open-hole tensile tests were performed in a previous investigation using the ${ }_{163}[90 / 0 / \pm 45]_{3 \mathrm{~s}}$ lay-up [5]. Specimens with five different hole diameters, $d=2 \mathrm{~mm}$, ${ }_{164} 4 \mathrm{~mm}, 6 \mathrm{~mm}, 8 \mathrm{~mm}, 10 \mathrm{~mm}$ and with a constant width-to-diameter ratio $(W / d)$ 165 equal to 6 were tested following the ASTM D-5766 standard [30]. All the 166 details of the tests performed and the test results are presented in [5].

${ }_{167}$ The comparison between the experimental results and the predictions of the 
finite fracture mechanics (FFM) previously described is shown in Figure 2 and in Table 2. The comparison includes the predictions obtained using the point stress (PS) model [6], which requires the inverse identification of the 'characteristic distance'. Using the test results of the specimen with a $6 \mathrm{~mm}$ diameter hole the characteristic distance is calculated as $0.83 \mathrm{~mm}$.

[Fig. 2 about here.]

[Table 2 about here.]

\begin{abstract}
The results shown in Figure 2 and in Table 2 indicate that the finite fracture mechanics model provides more accurate predictions than the point stress model. In addition, it should be stressed that, unlike the point stress model, the finite fracture mechanics model does not require any inverse identification from one of the tests.
\end{abstract}

To further validate the model proposed in this paper, additional experimental information on the open hole tensile strength of laminates manufactured using the same material system, Hexcel IM7-8552, is used. Green et al. [21] performed tests using the $[45 / 90 /-45 / 0]_{4 \mathrm{~s}}$ lay-up, with $W / d=5$ and hole diameters equal to $3.175 \mathrm{~mm}, 6.35 \mathrm{~mm}, 12.7 \mathrm{~mm}$, and $25.4 \mathrm{~mm}$. The unnotched strength reported for this lay-up is $X_{T}^{L}=929 \mathrm{MPa}$ [31]. However, there is no information regarding the mode I fracture toughness of this lay-up, a property required for the finite fracture mechanics model.

To estimate the value of $\mathcal{K}_{I c}$ the results of the test performed in the specimen with a $3.175 \mathrm{~mm}$ hole is used. Knowing the unnotched strength of the material and the notched strength of this test specimen it is possible to solve equation (1) for $l$ and $\mathcal{K}_{I c}$, which results in $\mathcal{K}_{I c}=42.3 \mathrm{MPa} \sqrt{\mathrm{m}}$. This value is close to 
211 of the geometry $\left(\bar{\sigma}_{N}=1-d / W\right)$. model.

[Fig. 3 about here.]

[Table 3 about here.]

As before, improved results are obtained using the finite fracture mechanics

Taking into account that the finite fracture mechanics model provides predictions of notched strength in a few of seconds, it can be used to generate design charts for notched laminates. Figure 4 shows the predicted normalized notched strength of the $[90 / 0 / \pm 45]_{3 \mathrm{~s}}$ laminate, defined as $\bar{\sigma}_{N}=\bar{\sigma}^{\infty} / X_{T}^{L}$, as a function of the $d / W$ ratio for different hole sizes. This Figure also includes the predictions obtained for a notch-sensitive material, whose normalized strength is a function of the stress concentration factor $K_{T}\left(\bar{\sigma}_{N}=1 / K_{T}\right)$, and the predictions for a notch-insensitive material, whose normalized strength is a function

[Fig. 4 about here.]

${ }_{213}$ Figure 4 shows that, for a constant $d / W$ ratio, the finite fracture mechanics 214 model predicts that the mechanical response of a notched composite laminate 

222 notch sensitivity factor is introduced:

$$
\eta_{N}=\frac{d}{l}
$$

223 where $l$ is calculated from the non-linear equation (10). This notch sensitivity 224 factor is equivalent to the dimensionless group introduced by Suo et al. [32] in 225 terms of the notch size, the material Young's modulus and unnotched strength, 226 and the crack opening displacement.

227 The finite fracture mechanics model is used to predict the notch sensitivity ${ }_{228}$ factor of the IM7-8552 $[90 / 0 / \pm 45]_{3 \mathrm{~s}}$ laminate with $W / d=6$ using two ad229 ditional extreme cases. The first one correspond to a ductile material with 230 a fracture toughness corresponding to twice that calculated for IM7-8552 ${ }_{231}[90 / 0 / \pm 45]_{3 \mathrm{~s}}\left(\mathcal{K}_{I c}=2 \times 48.0 \mathrm{MPa} \sqrt{\mathrm{m}}\right) ;$ the second case corresponds to a brittle 232 material with a fracture toughness corresponding to one-half of that previously ${ }_{233}$ used $\left(\mathcal{K}_{I c}=1 / 2 \times 48.0 \mathrm{MPa} \sqrt{\mathrm{m}}\right)$.

${ }_{234}$ Figure 5 shows the relation between the notch sensitivity factor and the hole 235 diameter for the three materials considered and Figure 6 shows the corre${ }_{236}$ sponding predicted relation between the hole diameter and the normalized 
strength.

[Fig. 5 about here.]

The previous figures demonstrate that the model developed in this work is use${ }_{254}$ fast and accurate method to predict the open-hole tensile strength of com255 posite laminates. Economic because it only requires the ply elastic constants 256 and two additional independent material properties: the laminate unnotched ${ }_{257}$ strength and the laminate fracture toughness. No inverse identification meth${ }_{258}$ ods are required. The predictions are obtained in a few seconds because no 259 finite element analysis or complex computational methods are required. Fi- 
${ }_{263}$ These characteristics of the model make it quite suitable for the generation of

271 priate for this type of laminates.

272 Future work will address the generalization of the model to deal with the 273 strength prediction of notched composite laminates subjected to multi-axial 274 loading.

\section{Acknowledgements}

This work was funded by AIRBUS under the project iComp - integrated method for the structural design of Composite components. The authors gratefully acknowledge the support provided by AIRBUS.

\section{References}

[1] Wisnom MR. Modelling discrete failures in composites with interface elements. Composites Part A: Applied Science and Manufacturing 2010;41(7):795-805. 
[2] Tay TE, Tan SHN, Tan VBC, Gosse JH. Damage progression by the elementfailure method (EFM) and strain invariant failure theory (SIFT). Composites Science and Technology 2005;65(6):935-944.

[3] van der Meer FP, Oliver C, Sluys LJ. Computational analysis of progressive failure in a notched laminate including shear nonlinearity and fiber failure. Composites Science and Technology 2010;70(4):692-700.

[4] Laurin F, Carrère N, Maire JF. A multiscale progressive failure approach for composite laminates based on thermodynamical viscoelastic and damage models. Composites-Part A 2007;38:198-209.

[5] Camanho PP, Maimí P, Dávila CG. Prediction of size effects in notched laminates using continuum damage mechanics. Composites Science and Technology 2007;67:2715-2727.

[6] Whitney JM, Nuismer RJ. Stress fracture criteria for laminated composites containing stress concentrations. Journal of Composite Materials 1974; 8:253265.

[7] Chang, FK, Scott, RA, Springer, GS. Strength of mechanically fastened composite joints. Journal of Composite Materials 1982;16:470-494.

[8] Camanho PP, Lambert M. A design methodology for mechanically fastened joints in laminated composite materials. Composites Science and Technology 2006;66:3004-3020.

[9] Bäcklund J. Fracture analysis of notched composites. Computers \& Structures 1981;13:145-154.

[10] Aronsson CG, Bäcklund J. Tensile fracture of laminates with cracks. Journal of Composite Materials 1986;20:287-307.

[11] Bäcklund J, Aronsson CA. Tensile fracture of laminates with holes. Journal of Composite Materials 1986;20:259-286. 
[12] Carlsson LA, Aronsson CG, Bäcklund J. Notch sensitivity of thermoset and thermoplastic laminates loaded in tension. Journal of Materials Science 1989;24:1670-1682.

[13] Leguillon D. Strength or toughness? A criterion for crack onset at a notch. European Journal of Mechanics A/Solids 2002;21:61-72.

[14] Cornetti P, Pugno N, Carpinteri A, Taylor D. Finite fracture mechanics: A coupled stress and energy failure criterion. Engineering Fracture Mechanics 2006;73:2021-2033.

[15] Andersons J, Tarasovs S, Sparnins E. Finite fracture mechanics analysis of crack onset at a stress concentration in a UD glass/epoxy composite in off-axis tension. Composites Science and Technology 2010;70:1380-1385.

[16] Hebel J, Dieringer R, Becker W. Modelling brittle crack formation at geometrical and material discontinuities using a finite fracture mechanics approach. Engineering Fracture Mechanics 2010;77:3558-3572.

[17] Carpinteri A, Cornetti P, Pugno N, Sapora A, Taylor D. A finite fracture mechanics approach to structures with sharp V-notches. Engineering Fracture Mechanics 2008;75:1736-1752.

[18] Taylor D, Cornetti P, Pugno N. The fracture mechanics of finite crack extension. Engineering Fracture Mechanics 2005;72:1021-1038.

[19] Müller A, Becker W, Stolten D, Hohe J. A hybrid method to assess interface debonding by finite fracture mechanics. Engineering Fracture Mechanics 2006;73:994-1008.

[20] Martin E, Leguillon D, Carrère N. A twofold strength and toughness criterion for the onset of free-edge shear delamination in angle-ply laminates. International Journal of Solids and Structures 2010;47:1297-1305. 
[21] Green BG, Wisnom MR, Hallet SR. An experimental investigation into the tensile strength scaling of notched composites. Composites-Part A 2007;38:867878.

[22] Tan SC. Stress concentrations in laminated composites. Technomic, 2004.

[23] Newman JC Jr. A nonlinear fracture mechanics approach to the growth of small cracks. In: Proceedings of AGARD Conference 1983;328(6).

[24] Tsai SW, Ha S, Tay TE, Miyano Y, Sihn S. Strength \& Life of Composites. In: Tsai SW, editor. U.S.A. Aeronautics \& Astronautics, Stanford University, 2008.

[25] Kreyszig E. Advanced Enginnering Mathmathics. John Wiley and Sons, 1993.

[26] Bao G, Ho S, Suo Z, Fan B. The role of material orthotropy in fracture specimens for composites. International Journal of Solids and Structures 1992;29:1105-1116.

[27] Standard test method for tensile properties of polymer matrix composite materials, ASTM D 3039/D 3039M-00. American Society for Testing and Materials (ASTM). West Conshohocken, PA, U.S.A.

[28] Standard test method for in-plane shear response of polymer matrix composite materials by test of a $\pm 45^{\circ}$ laminate, ASTM D 3518/3518M-94. American Society for Testing and Materials (ASTM). West Conshohocken, PA, U.S.A.

[29] Camanho PP, Catalanotti G. On the relation between the composite laminate fracture toughness and that of the $0^{\circ}$ ply fracture toughness: analytical model and experimental validation. Engineering Fracture Mechanics 2011;78:25352546 .

[30] Open hole tensile strength of polymer composite laminates, ASTM D 5766/D 5766M-02a. American Society for Testing and Materials (ASTM). West Conshohocken, PA, U.S.A. 
[31] Wisnom M, Khan B, Hallett S. Size effects in unnotched tensile strength of unidirectional and quasi-isotropic carbon/epoxy composites. Composite Structures 2008;84:21-28.

[32] Suo Z, Ho S, Gong X. Notch ductile-to-brittle transition due to localized inelastic band. J. of Engineering Materials and Technology 1993;115: 319-326. 


\section{List of Figures}

1 Notched laminate under tensile loading.

2 Comparison between predictions and experiments $[90 / 0 / \pm 45]_{3 \text { s lay-up. }}$

3 Comparison between predictions and experiments $[45 / 90 /-45 / 0]_{4 \mathrm{~s}}$ lay-up.

4 Design chart for IM7-8552 [90/0/ \pm 45$]_{3 \mathrm{~s}}$ laminates.

5 Notch sensitivity factor calculated using finite fracture mechanics.

6 Predicted normalized strength for different materials. 


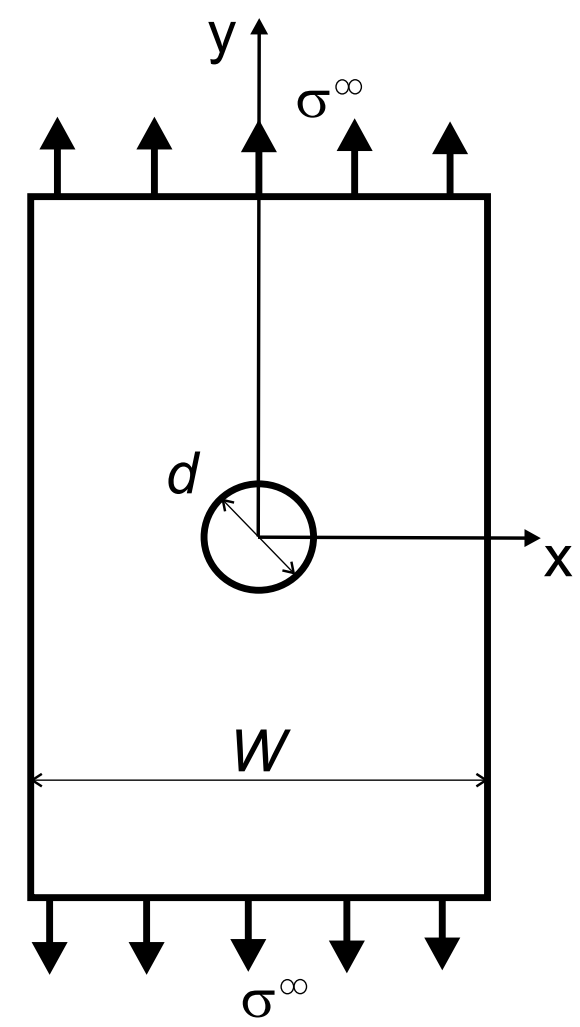

Fig. 1. Notched laminate under tensile loading. 


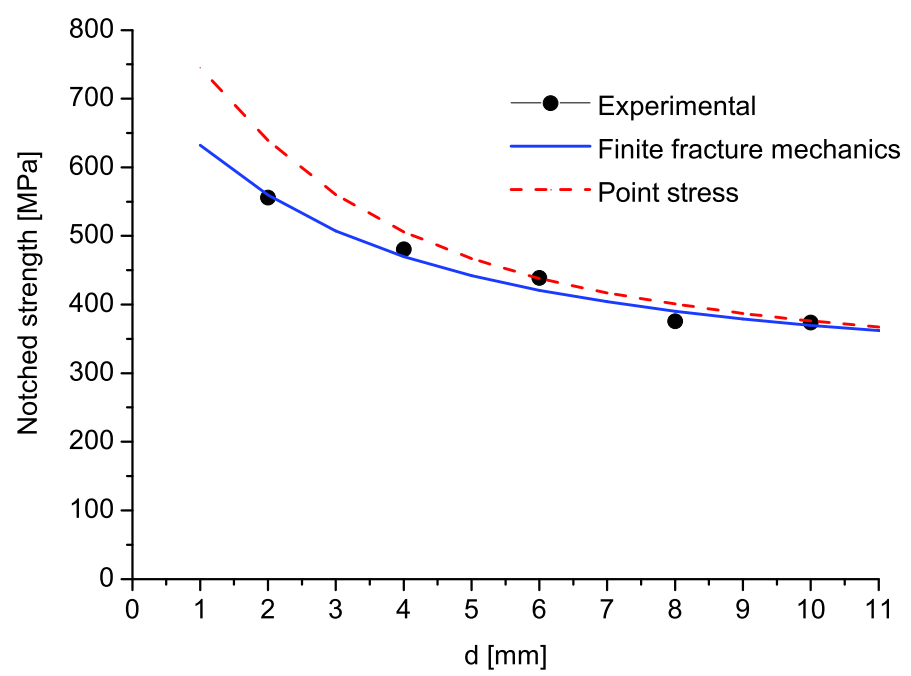

(a) Notched strength vs. hole diameter.

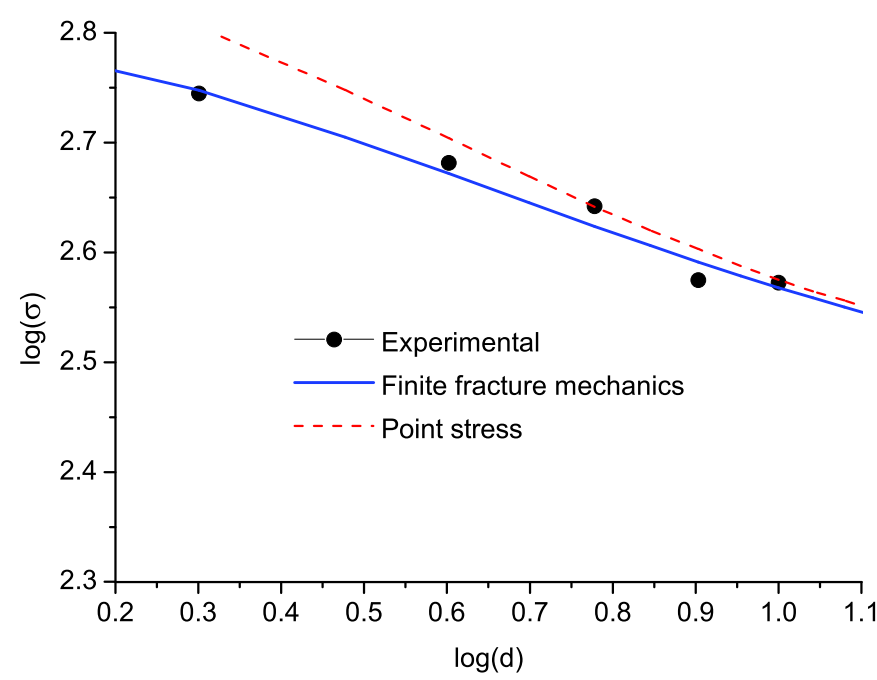

(b) Notched strength vs. hole diameter (logarithmic scale).

Fig. 2. Comparison between predictions and experiments - $[90 / 0 / \pm 45]_{3 \mathrm{~s}}$ lay-up. 


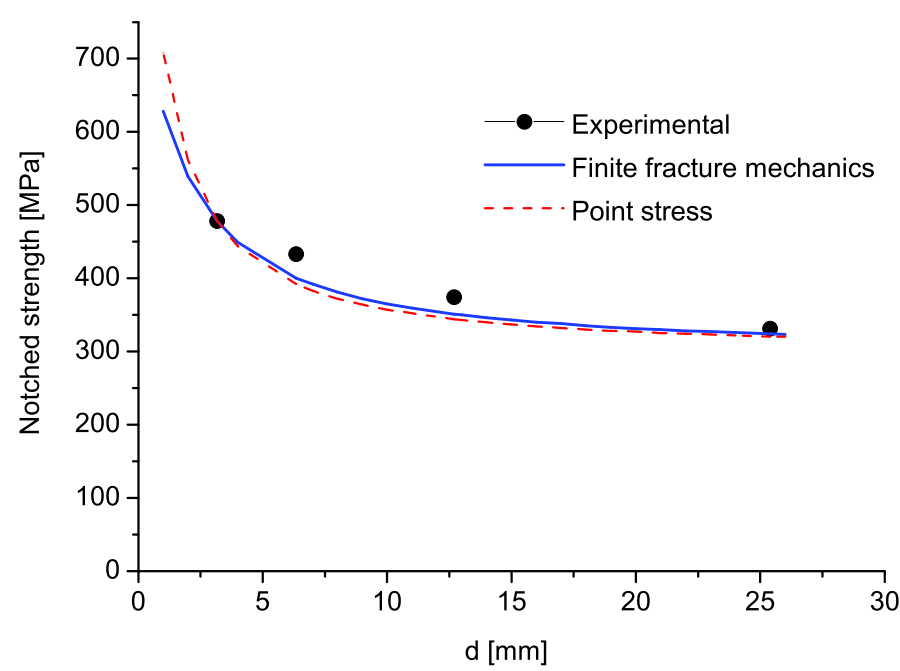

(a) Notched strength vs. hole diameter.

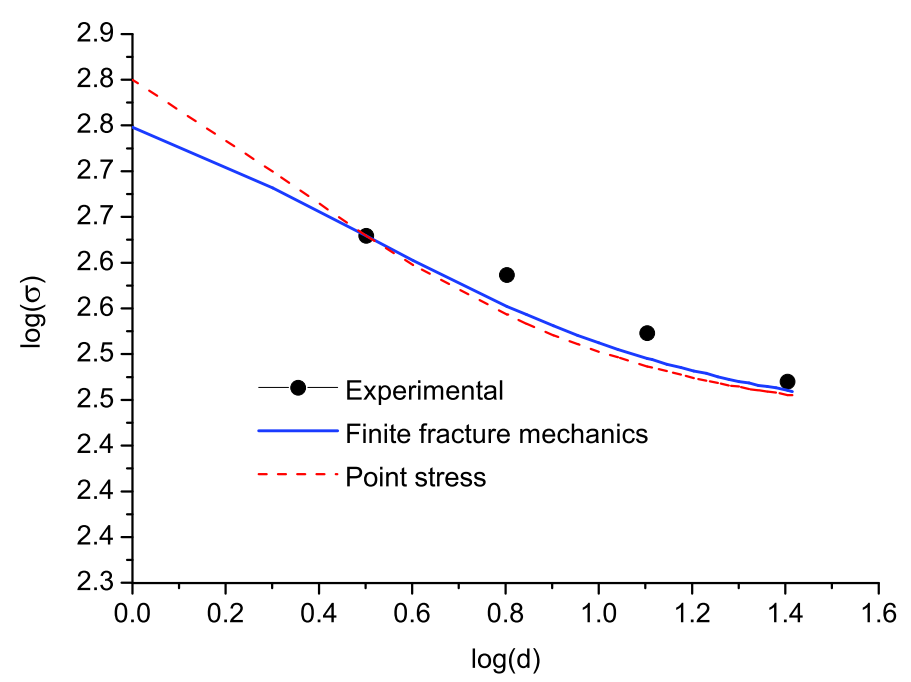

(b) Notched strength vs. hole diameter (logarithmic scale).

Fig. 3. Comparison between predictions and experiments - $[45 / 90 /-45 / 0]_{4 s}$ lay-up. 


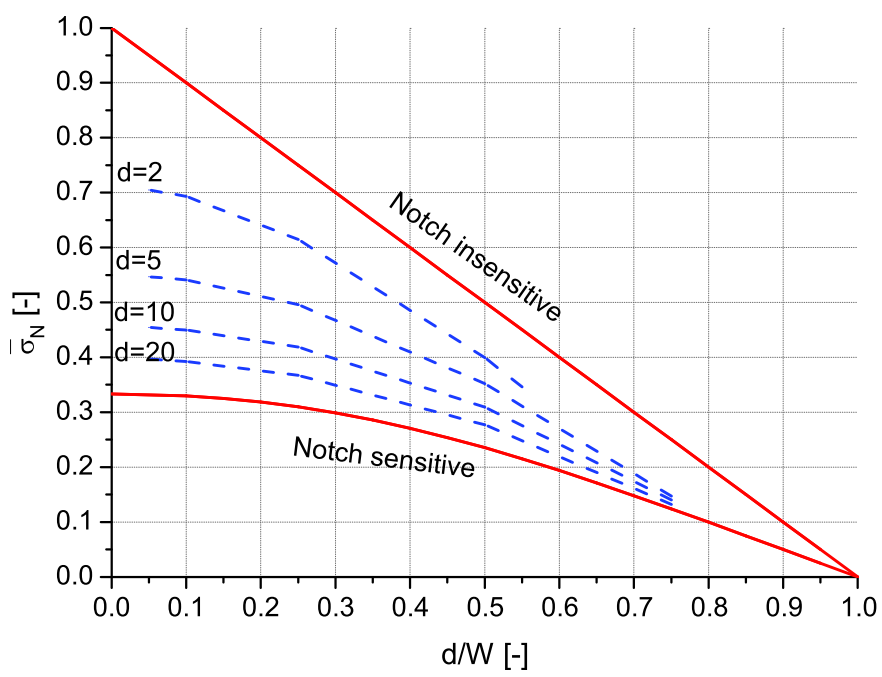

Fig. 4. Design chart for IM7-8552 [90/0/ \pm 45$]_{3 \mathrm{~s}}$ laminates. 


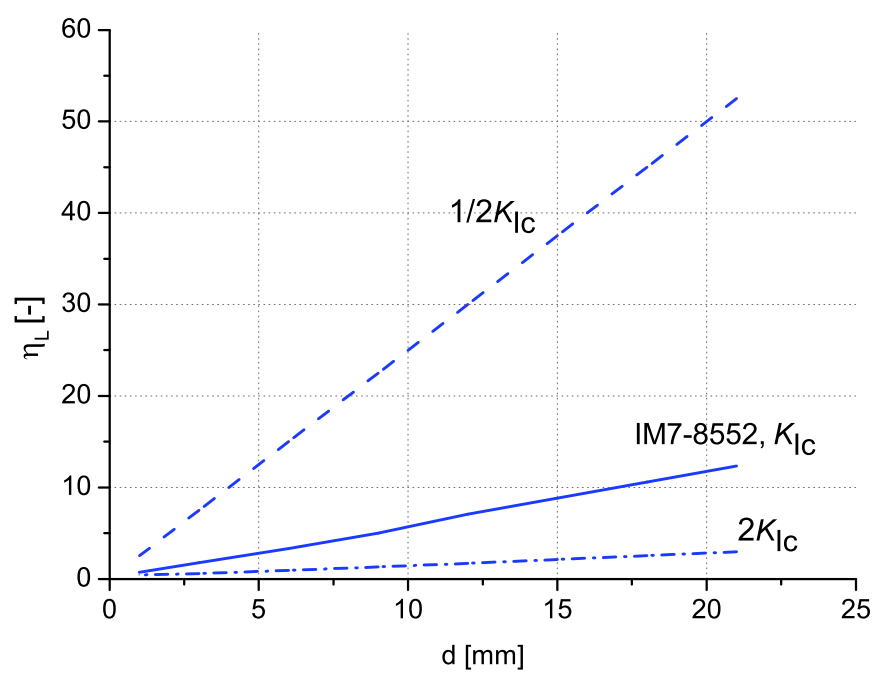

Fig. 5. Notch sensitivity factor calculated using finite fracture mechanics. 


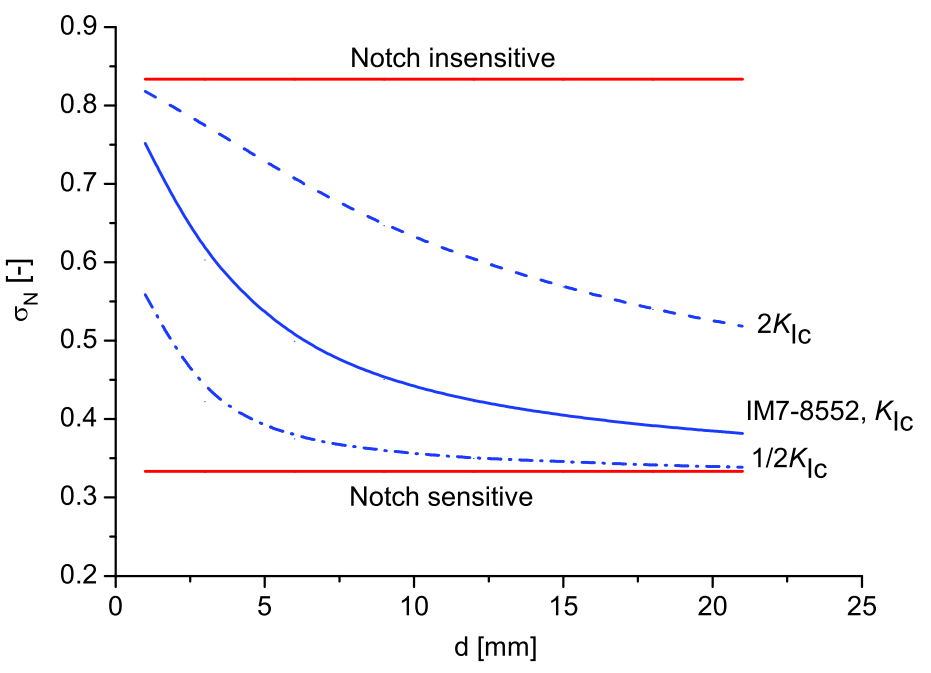

Fig. 6. Predicted normalized strength for different materials. 


\section{List of Tables}

$\begin{array}{lll}1 & \text { Ply elastic properties. } & 28\end{array}$

2 Comparison between predictions and experiments for the $[90 / 0 / \pm 45]_{3 \mathrm{~s}}$ lay-up.

3 Comparison between predictions and experiments for the $[45 / 90 /-45 / 0]_{4 \mathrm{~s}}$ lay-up. 
Table 1

Ply elastic properties.

\begin{tabular}{llll}
\hline \hline Property & Standard & Mean value & STDV \\
\hline$E_{1}[\mathrm{GPa}]$ & Ref. [27] & 171.4 & 2.38 \\
$E_{2}[\mathrm{GPa}]$ & Ref. [27] & 9.1 & 0.09 \\
$G_{12}[\mathrm{GPa}]$ & Ref. [28] & 5.3 & 0.13 \\
$\nu_{12}$ & Ref. [27] & 0.3 & 0.02 \\
\hline \hline
\end{tabular}


Table 2

Comparison between predictions and experiments for the $[90 / 0 / \pm 45]_{3 \mathrm{~s}}$ lay-up.

\begin{tabular}{llllll}
\hline \hline $\mathrm{d}[\mathrm{mm}]$ & $\bar{\sigma}^{\infty}$ (Exp.) $[\mathrm{MPa}]$ & $\bar{\sigma}^{\infty}(\mathrm{FFM})[\mathrm{MPa}]$ & Error $(\%)$ & $\bar{\sigma}^{\infty}(\mathrm{PS})[\mathrm{MPa}]$ & Error $(\%)$ \\
\hline 2 & 555.7 & 560 & +0.7 & 639 & +15.0 \\
4 & 480.6 & 470 & -2.2 & 506 & +5.3 \\
6 & 438.7 & 420 & -4.1 & $\mathrm{n} / \mathrm{a}$ & $\mathrm{n} / \mathrm{a}$ \\
8 & 375.7 & 390 & +3.8 & 401 & +6.7 \\
10 & 373.7 & 370 & -1.1 & 376 & +0.6 \\
\hline \hline
\end{tabular}


Table 3

Comparison between predictions and experiments for the $[45 / 90 /-45 / 0]_{4 \mathrm{~s}}$ lay-up.

\begin{tabular}{llllll}
\hline \hline $\mathrm{d}[\mathrm{mm}]$ & $\bar{\sigma}^{\infty}$ (Exp.) [MPa] & $\bar{\sigma}^{\infty}(\mathrm{FFM})[\mathrm{MPa}]$ & Error $(\%)$ & $\bar{\sigma}^{\infty}(\mathrm{PS})[\mathrm{MPa}]$ & Error $(\%)$ \\
\hline 3.175 & 478 & $\mathrm{n} / \mathrm{a}$ & $\mathrm{n} / \mathrm{a}$ & $\mathrm{n} / \mathrm{a}$ & $\mathrm{n} / \mathrm{a}$ \\
6.35 & 433 & 400 & -7.6 & 392 & -9.5 \\
12.7 & 374 & 351 & -6.1 & 344 & -8.0 \\
25.4 & 331 & 324 & -2.1 & 320 & -3.3 \\
\hline \hline
\end{tabular}

